\title{
MULTI-DRUG APPROACHES TO NASH: WHAT'S IN THE DEVELOPMENT PIPELINE?
}

Michael Johnston ${ }^{1}$, Janisha Patel ${ }^{1}$, Christopher D Byrne ${ }^{2,3}$

${ }^{1}$ Department of Hepatology, University Hospital Southampton NHS Foundation Trust, Southampton, UK. ORCID: 0000-0002-4704-8349 (MPJ); 0000-0002-4634-0751 (JP).

${ }^{2}$ Human Development and Health, Faculty of Medicine, University of Southampton, Southampton, UK. ORCID

${ }^{3}$ National Institute for Health Research Southampton Biomedical Research Centre, University of Southampton and University Hospital Southampton National Health Service (NHS) Foundation Trust, Southampton, UK. ORCID: 0000-0001-6322-7753 (CDB).

\section{INTRODUCTION}

Non-alcoholic fatty liver disease (NAFLD) was first described over 40 years ago. ${ }^{1}$ In subsequent years it has become clear that obesity is an important risk factor for NAFLD ${ }^{2}$, and that NAFLD increases the risk of type 2 diabetes (T2DM) and cardiovascular disease (CVD) ${ }^{3}$.

With the 'rising tide' of obesity, the prevalence of NAFLD has recently been estimated to affect up to a quarter of the global adult population. ${ }^{4}$ With such a high prevalence of NAFLD, the numbers of patients with more severe liver disease, i.e. non-alcoholic steatohepatitis (NASH), in whom progression to advanced fibrosis, cirrhosis, decompensated liver disease, or hepatocellular carcinoma may occur, has increased markedly. This burden of disease is also markedly increasing the numbers of NASH liver transplant registrants ${ }^{5}$ with important implications for the provision of health care services.

To date, the existing evidence shows that two drugs (pioglitazone and liraglutide) that are licensed for the treatment of T2DM, and that principally act in adipose tissue, may benefit a proportion of patients with $\mathrm{NASH}$. Although these drugs do not improve NASH in all patients, notably, treatment with both drugs confers benefits beyond the liver in treating T2DM and reducing risk of CVD. ,, $7^{2}$

Thus, for new drugs in the NASH-treatment pipeline, given the increased extra-hepatic morbidity and mortality associated with NAFLD, it is now important that any benefits (or harms) beyond the liver are described. We consider that the paradigm for the ideal drug in NASH would be an agent that not only ameliorated NASH but also benefitted T2DM and CVD (see Figure 1). In this commentary, we describe a number of promising new pharmacological agents identified from preclinical models and early phase trials that may benefit NASH (summarized in Table 1). In Table 1 we also describe the potential benefits (and harms) of these drugs for T2DM and CVD.

\section{DRUGS IN DEVELOPMENT FOR THE TREATMENT OF NASH}

We have chosen to divide the drugs that benefit NASH according to whether their principle mode of action is on steatosis, or steatohepatitis and fibrosis.

\subsection{STEATOSIS}

Fatty infiltration of the liver (hepatic steatosis), may be isolated or progress to an inflammatory process of hepatocyte ballooning and lobular inflammation. Manipulation of fatty acid metabolism 
through an array of mechanisms is a promising strategy for abating this pathological process. Although incompletely understood, targeting bile acid synthesis is one approach that directly influences cholesterol metabolism and benefits NASH. NGM-282 is an analogue of fibroblast growth factor 19 (FGF-19) which has been studied in a phase II trial of patients with a histological diagnosis of NASH. Patients who received NGM-282 achieved $58 \%$ and $67 \%$ relative reduction in liver fat at 12 weeks at low and high doses respectively. ${ }^{8}$ In addition to its effect on steatosis, NGM-282 significantly improved fibrosis score by $\geq 1$ point, without worsening of steatohepatitis.

FGF-19 regulates bile acid synthesis, glycogen synthesis and gluconeogenesis as well as affecting a reduction in adipose tissue. ${ }^{9}$ FGF-19 has an integral role in the downregulation of bile acid synthesis through inhibition of cholesterol 7a-hydroxylase. ${ }^{10}$ However, there are side effects of treatment, potentially limiting the usefulness of FGF-19 treatment. Firstly, diarrhoea was a sideeffect of FGF-19. Diarrhoea was managed by 'separating the timing of injection around meals and decreasing meal size', and one might speculate that this side-effect resulted in weight loss and thereby decreased liver fat content. Secondly, the increase in serum low-density lipoprotein cholesterol (LDL-C) caused by FGF-19 is undesirable in a patient group in whom cardiovascular risk reduction is of paramount importance. The increase in LDL-C concentration was reduced by treatment with the HMG-CoA reductase inhibitor rosuvastatin. ${ }^{11}$ However, we would be cautious about inferring that statins negate all of the adverse effect of NGM-282 on cardiovascular risk, since it is well accepted that treatment of increased LDL-C concentrations with statins does not attenuate all of the increased CVD risk in patients with increased LDL-C concentrations.

A beneficial effect on hepatic fat content has also been demonstrated by another member of the FGF family, FGF-21. Pegbelfermin (BMS-986036) is a pegylated subcutaneous recombinant analogue of FGF-21 which, in a phase II study of 75 overweight/obese patients, showed a significant decrease in hepatic fat fraction compared to placebo over 16 weeks. ${ }^{12}$ There was no significant weight change in both placebo and intervention arms of the study. There was a trend towards improvement in LDL-C and high-density lipoprotein cholesterol (HDL-C) concentrations, which although not statistically significant, was consistent with a previous proof-of-concept study demonstrating favourable metabolic effects with treatment. ${ }^{13}$

Hepatic thyroid hormone receptor beta (THR- $\beta$ ) is a novel target for reducing lipotoxic fatty acids in the steatotic hepatocyte. Findings from a phase II study in patients with NAFLD treated with the THR- $\beta$ agonist VK2809 were presented at the European Association for the Study of the Liver (EASL) International Liver Congress (ILC) 2019. This study demonstrated a median relative reduction in liver fat of $>50 \%$ compared to $9.4 \%$ by placebo. ${ }^{14} \mathrm{~A}$ phase II multi-centre randomised double-blind placebo-controlled trial of patients with biopsy-proven NASH assessed the effect of a similar agent THR- $\beta$ agonist MGL-3196. The findings were presented the EASL ILC 2018. MGL3196 reduced hepatic fat content compared to placebo (AR -7.6\% vs $-1.6 \%$ ). ${ }^{15}$ These two encouraging studies herald THR- $\beta$ agonism as a potential therapeutic mechanism for treating NAFLD. We cautiously await more complete peer reviewed reporting of the results of these studies, including data on any adverse events, particularly on the metabolic profile, given animal data has previously demonstrated impaired insulin sensitivity. ${ }^{16}$

Increased de novo lipogenesis (DNL) may contribute to dysregulated fatty acid biosynthesis leading to NAFLD/NASH. ${ }^{17}$ GS-0976 is an inhibitor of acetyl-coenzyme A carboxylase (ACC), the rate limiting enzyme in fatty acid synthesis. In a phase II placebo-controlled trial, GS-0976 achieved the primary outcome of $>30 \%$ reduction in hepatic fat content measured by quantification of magnetic 
resonance imaging-proton density fat fraction (MRI-PDFF). ${ }^{18}$ Unfortunately an unfavourable increase in triglycerides was noted in the treatment arm. There are also currently two registered trials of GS-0976 treatment as part of combination therapy in NASH with both the ASK-1 inhibitor Selonsertib and the farnesoid X-activated receptor (FXR) agonist GS-9674 (NCT03449446, NCT03987074). Neither trial is recruiting yet.

\subsection{STEATOHEPATITIS \& FIBROSIS}

There are a number of promising agents which ameliorate the inflammatory component of NASH. The peroxisome proliferator-activated receptor (PPAR)- $\alpha$ and $-\delta$ agonist Elafibranor is one such agent. Although Elafibranor treatment did not meet the primary endpoint of improvement in NAFLD Activity Score (NAS) without worsening of fibrosis, it did produce a significant improvement in reduction of higher NAS compared to placebo, in post hoc analysis. ${ }^{19}$ Furthermore there were significant decreases in $\mathrm{LDL}-\mathrm{C}$, triglycerides and $\mathrm{HbA} 1 \mathrm{c}$ concentrations. We eagerly await the outcome of the currently registered trial assessing relative effect of Elafibranor on saturated fatty acids in the liver measured by MR spectroscopy (NCT03953456).

For many of the therapeutic agents studied in NASH the anti-inflammatory and anti-fibrotic mechanisms are inextricably linked. Their combined improvement is the primary endpoint in many relevant drug trials. Down-regulation of migration and infiltration of monocytes, macrophages and collagen-promoting hepatic stellate cells formed the basis of the theory behind the rationale for the CENTAUR trial. Antagonism of the CC chemokine receptor types 2 and 5 (CCR2/CCR5) by Cenicriviroc targeted anti-inflammatory and anti-fibrotic mechanisms thought to be beneficial in the amelioration of NASH. ${ }^{20}$ CENTAUR was a randomized placebo-controlled trial of 289 patients with NASH who had a NAS $\geq 4$ and liver fibrosis stages 1-3. The primary outcome was a $\geq 2$ point improvement in NAS with no worsening of fibrosis at one year. Disappointingly there was not a significant difference in primary outcome between the study drug Cenicriviroc and placebo (16\% vs $19 \%)$. However, the secondary outcome of fibrosis improvement alone attributable to Cenicriviroc was met $\left(20 \%\right.$ of patients benefitting in the treatment arm vs $10 \%$ in the placebo arm). ${ }^{20}$ Furthermore, no improvement in the metabolic profile was seen in the intervention arm, despite the theory that decreasing macrophage recruitment into adipose tissue via CCR2 antagonism, could benefit insulin resistance. There is an active phase II trial of Cenicriviroc as combination therapy with the FXR agonist Tropifexor in patients with NASH and F2/F3 fibrosis (NCT03517540).

Inhibiting apoptosis signal-regulating kinase 1 (ASK-1) with Selonsertib was the subject of a phase II trial assessing the antifibrotic effect of this treatment in patients with NASH and stage 2-3 liver fibrosis. ${ }^{21}$ Selonsertib was administered alone and in combination with the lysl oxidase-like molecule 2 (LOXL-2) monoclonal antibody Simtuzumab. $43 \%$ of patients on high dose Selonsertib had $\geq 1$ fibrosis stage reduction, compared to $20 \%$ of patients in the Simtuzumab alone group. These improvements in fibrosis correlated with liver stiffness reduction on magnetic resonance elastography (MRE). In the absence of a control group, these results need to be verified in further placebo-controlled trials. We have mentioned above that there is an active trial of Selonsertib in combination therapy, although this trial is not yet recruiting (NCT03449446).

The Caspase-inhibitor Emricasan targets apoptosis and has potential anti-inflammatory effects. A phase II trial which randomised 19 patients with NAFLD to both Emricasan and placebo showed improvement in serum ALT and surrogate biomarkers of apoptosis. ${ }^{22}$ However, the complete results 
from the larger trials with Emricasan are pending. ENCORE-PH enrolled patients with NASH and hepatic venous pressure gradient (HVPG) > 12mmHg (NCT02960204) and ENCORE-NF enrolled patients with biopsy proven NASH and F1-F3 (NCT02686762). Unfortunately, a recent press release announced failure of the intervention to meet the primary endpoint of $\geq 1$ fibrosis stage improvement without worsening of steatohepatitis. ${ }^{23}$

Finally, with regard to improvement in fibrosis stage without worsening in $\mathrm{NASH}$, it is important to discuss obeticholic acid (OCA) ${ }^{24}$ FLINT $^{25}$ was a multi-centre, double-blind, randomised, placebocontrolled phase 2 trial of OCA in patients with biopsy-proven NASH. The primary outcome in FLINT was improvement in NAS without worsening in fibrosis. This was based on liver histological examination after 72 weeks of treatment with either OCA or placebo. FLINT demonstrated that patients treated with OCA achieved the primary outcome in 50/110 patients $(50 \%)$ compared to placebo which achieved the primary outcome in 23/109 (21\%) of patients. This extremely promising result was however tempered by an increase in the side-effect of pruritus, which occurred in $23 \%$ of patients in the OCA arm and $6 \%$ of patients in the placebo arm. FLINT also showed that OCA treatment produced a marked increase in LDL-C concentration. Despite lipid-lowering therapy an increase in LDL-C concentration persisted at 72 weeks in the OCA group compared to the placebo group.

Following on from the FLINT trial, REGENERATE is a phase 3, multi-centre, randomized, placebocontrolled trial testing the effects of OCA in NASH. The 18 month interim analysis was presented at EASL ILC 201924. The results (presented at EASL ILC 2019) demonstrated that REGENERATE is currently meeting the primary outcome of improvement in fibrosis score by $\geq 1$ stage with no worsening in NASH. (However, it should also be noted that the previously shown improvement in NAS was not demonstrated). Deterioration in lipid profile was also observed in a dose-dependent manner. Pruritus was the most common adverse event (19\% placebo, $28 \%$ OCA $10 \mathrm{mg}, 51 \%$ OA $25 \mathrm{mg}$ ). Nonetheless, it is possible that OCA will be the first therapeutic agent to be approved for treatment of NASH with fibrosis, based on these interim analysis results.

\section{FUTURE STRATEGIES: COMBINATION THERAPY}

It is noteworthy that to date, none of the agents that have shown efficacy in randomized placebocontrolled trials in $\mathrm{NASH}$, have benefitted all of the treated patients. In trying to understand the explanation(s) for this observation, in contrast to trials testing agents for CVD prevention, trials in $\mathrm{NASH}$ have been undertaken with small numbers of participants. Consequently, post-hoc sub-group analyses have provided little extra insight into whether specific groups of participants benefit (or not). That said, it is highly likely that the reason for beneficial treatment effects, (or for the failure of treatment efficacy) reflects the complex and varied pathogenesis of liver disease within the spectrum of conditions encapsulated by NAFLD. Put simply, the drivers of disease development and progression in NASH are likely to vary between patients. For example, the pathogenesis of NASH in a normal weight, 40-year-old man who has the patatin-like phospholipase domain-containing protein 3 (PNPLA3) 148 GG genotype, is likely to be very different from the pathogenesis of NASH in an obese, 60 year old women, with type 2 diabetes with no genotypic predisposition to developing $\mathrm{NASH}$. Since the pathogenesis of NASH is influenced by extra-hepatic organs, (e.g. adipose tissue and the intestine), it will also be important to consider the relative influence of treatments in these organs too. Consequently, and analogous to the treatment of hypertension, it is likely that effective 
treatments for $\mathrm{NASH}$, will initially involve trials of combination therapies. Having identified combinations of treatments with proven efficacy, these will need to be tailored to individual patients' requirements, according to their phenotypic and genotypic characteristics.

In Table 2 we have summarized registered trials of combination therapy that are either being planned or are actively recruiting. Although to date, only pioglitazone therapy and vitamin $E$ treatment are two agents with proven efficacy in NASH (recommended for consideration of treatment of $\mathrm{NASH}$ by international guidelines), perhaps because these agents are inexpensive, generically available drugs, it is important to note (see Table 2) that there are few combination therapy trials sponsored by Industry, that are utilizing either of these drugs. Although licensed for the treatment of type 2 diabetes, pioglitazone has recently been recommended by three separate international Guidelines for the treatment of NASH. ${ }^{26-28}$ Pioglitazone is also the only recommended $\mathrm{NASH}$ drug that targets both adipose tissue metabolism and inflammation, acting through the transcription factor peroxisome proliferator activated receptor gamma (PPAR- $\mathrm{y}$ ). However, pioglitazone is known to work in only $\sim 50 \%$ of patients (regardless of diabetes status) ${ }^{29-32}$ and weight gain is a noted side-effect. Therefore, combining pioglitazone with an agent that would counter the weight gain may be a useful therapeutic strategy for combination therapy. Pioglitazone has also been shown to confer additional benefits to treat T2DM and decrease risk of myocardial infarction and stroke. ${ }^{33,34}$ Previous concerns that pioglitazone may increase risk of heart failure may have been overstated and the results of the recent Insulin Resistance Intervention after Stroke (IRIS) trial show that the lower dose of pioglitazone (i.e. $30 \mathrm{mg} /$ day) is not associated with any increased risk of heart failure. ${ }^{35}$ Liraglutide is a GLP-1 agonist which facilitates weight loss and that has also been shown to provide benefit in NASH. ${ }^{36}$ Consequently, combination therapy with pioglitazone and liraglutide would seem to be a sensible combination therapy that is not currently being tested in $\mathrm{NASH}$.

\section{CONCLUSION}

We have described a selection of agents for NAFLD in early phase trials which show favourable effects on hepatic steatosis, steatohepatitis or fibrosis. Whereas we acknowledge that any future decision on accelerated approval of these drugs for NAFLD is currently based upon improvements in liver fibrosis and/or steatohepatitis, we want to draw particular attention to the cardiometabolic effects of these newer agents. There is considerable heterogeneity of the patient phenotype in subjects with NASH, and it will be important not to treat NASH with a new agent that increases CVD risk. Patients with NASH have varying profiles of risk for both hepatic and extrahepatic diseases, such as T2DM and CVD. Eventually treatment of NAFLD may become tailored and based on more accurate and nuanced risk prediction for both liver disease and closely associated extra-hepatic conditions. Given that it is now accepted that the risk of dying from CVD is at least as great, if not greater, than dying from liver-related mortality, treatments that both target the liver and the common extrahepatic diseases are highly attractive potential treatment strategies for NASH. In that sense, there is already good evidence that treatment with pioglitazone in carefully selected patients (who are not at risk of fracture or cardiac failure) fulfills many of these criteria. We consider that future trials of new agents for NASH needs to very carefully assess their impact beyond the liver and on cardiometabolic risk factors and extra-hepatic diseases such as T2DM and CVD. 


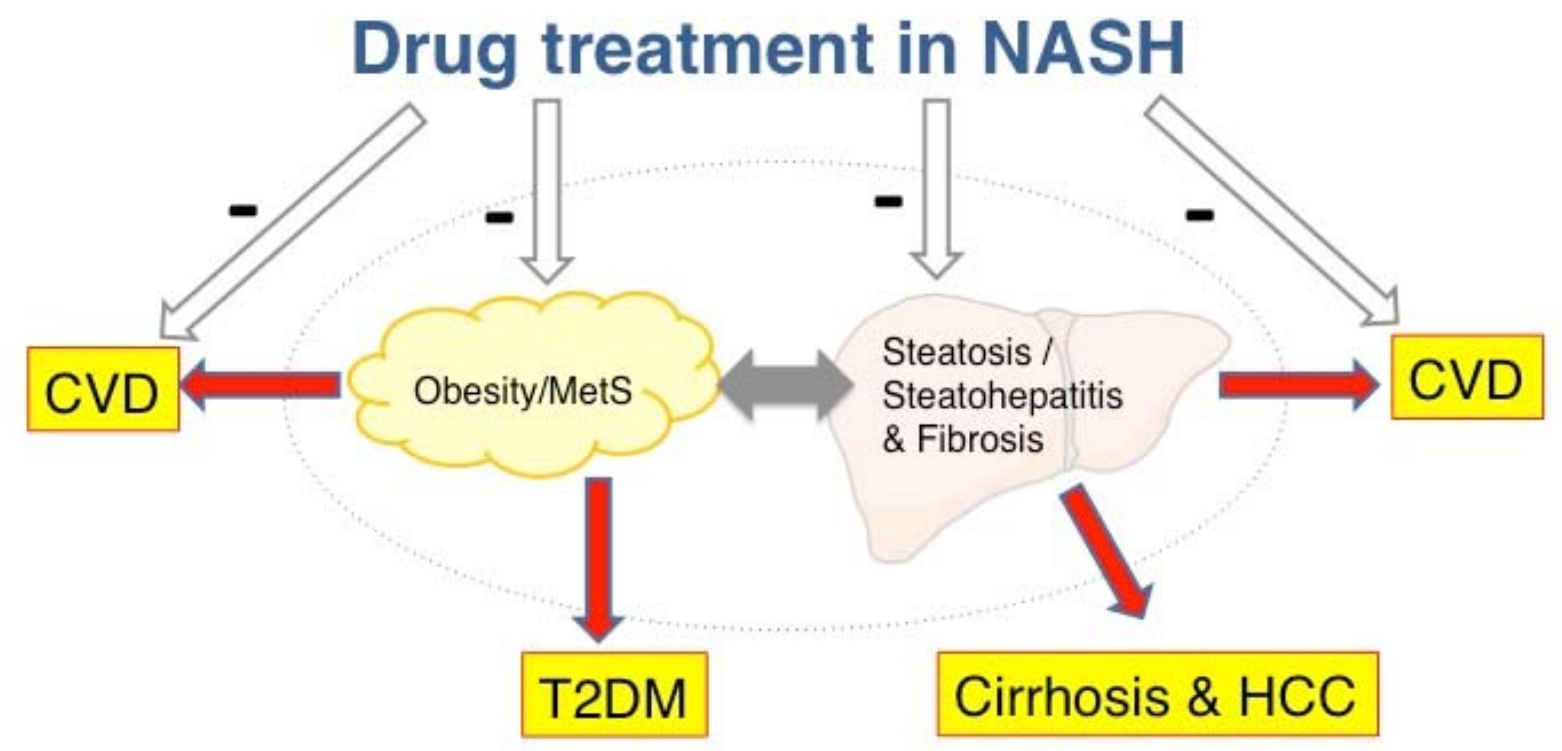

Figure 1 The aim of future drug treatment in NASH

Abbreviations: CVD, cardiovascular disease; HCC, hepatocellular carcinoma; MetS, Metabolic syndrome; T2DM, type 2 diabetes.

\section{EXPERT OPINION}

The ideal therapeutic agent(s) in NASH would not only ameliorate liver disease but also treat/prevent multi-morbidity (e.g. T2DM or CVD) associated with NASH. We have described a selection of drugs which have shown promise in early phase clinical trials in $\mathrm{NASH}$, as well as registered trials of combination therapy (Table 2). However, amongst the existing drugs that have been shown to benefit $\mathrm{NASH}$, as mentioned above, pioglitazone has been shown to be effective in treating $\sim 50 \%$ of patients with $\mathrm{NASH} .{ }^{32}$

Pioglitazone has become the forgotten, cost effective drug with cardiovascular benefits in the treatment of T2DM. ${ }^{6}$ Given additional benefits of pioglitazone treatment on the liver in NASH that have been confirmed in meta-analysis ${ }^{32}$ pioglitazone provides a good bench mark by which other newer drugs should be judged and which should be used in testing combinations of therapies in $\mathrm{NASH}$. In our opinion, any new drugs that are shown to confer benefit on liver disease in NASH, must also test whether these agents are beneficial (or harmful) for T2DM and CVD. For the future, we believe the treatment of NASH will become analogous to the treatment of hypertension as it is highly likely that multiple different classes of drugs targeting different mechanistic pathways will be needed as no single agent is likely to be able to control all aspects of this complex liver disease. 

Table 1 Selected phase I/II trials of agents in NAFLD/NASH

DRUG MECHANISM PHASE OUTCOME MEASURES

EFFECTS ON LIVER

STEATOSIS

STEATO-

HEPATITIS

EFFECTS

RELEVANT TO

T2DM \& CVD

\begin{tabular}{|c|c|c|c|c|c|c|c|c|}
\hline NGM 282 & $\begin{array}{l}\text { FGF-19 } \\
\text { analogue }\end{array}$ & II & $\begin{array}{l}\text { Histological } \\
\text { improvement in NAS }(\geq 2) \\
\text { and no worsening of } \\
\text { fibrosis } \\
\text { MRI-PDFF, MRI-cT1, } \\
\text { ELF, C4, bile acids, AST, } \\
\text { ALT }\end{array}$ & Decrease & Decrease & Decrease & -Increased LDL-C & $\begin{array}{l}\text { - Gl symptoms } \\
\text { nost common SEs } \\
\text { (diarrhea, nausea, } \\
\text { frequent bowel } \\
\text { novements, } \\
\text { abdominal pain) }\end{array}$ \\
\hline Pegbelfermin & $\begin{array}{l}\text { FGF-21 } \\
\text { analogue }\end{array}$ & II & $\begin{array}{l}\text { - Safety profile } \\
\text {-Absolute change } \\
\text { in hepatic fat on } \\
\text { MRI-PDFF }\end{array}$ & Decrease & $N A$ & $N A$ & $\begin{array}{l}\text { - Suggested } \\
\text { decrease in } \\
\text { triglycerides } \\
\text { Suggested } \\
\text { decrease in LDL-C }\end{array}$ & $\begin{array}{l}\text { GI symptoms } \\
\text { most common } \\
\text { SEs } \\
-7 \% \text { treatment } \\
\text { emergent grade } 3 \\
\text { laboratory } \\
\text { abnormality }\end{array}$ \\
\hline VK2809* & THR- $\beta$ agonist & II & $\begin{array}{l}\text { Safety profile } \\
\text { - Reduction in } \\
\text { hepatic fat content } \\
\text { on MRI-PDFF }\end{array}$ & Decrease & $N A$ & $N A$ & $\begin{array}{l}\text { No data - await } \\
\text { complete results }\end{array}$ & $\begin{array}{l}\text {-No SAEs } \\
\text { reported }\end{array}$ \\
\hline MGL-3196* & THR- $\beta$ agonist & II & $\begin{array}{l}\text { - Relative reduction in } \\
\text { hepatic fat on MRI-PDFF } \\
\text {-Improved histology; } \\
\text { Lipids; ALT, AST. }\end{array}$ & Decrease & $N A$ & $N A$ & $\begin{array}{l}\text { Decreased LDL-C } \\
\text { - Decreased } \\
\text { triglycerides }\end{array}$ & $\begin{array}{l}\text { } 3 \text { SAEs which } \\
\text { occurred were } \\
\text { considered } \\
\text { unrelated }\end{array}$ \\
\hline
\end{tabular}




\begin{tabular}{|c|c|c|c|c|c|c|c|c|}
\hline GS-0976 & ACC inhibitor & II & $\begin{array}{l}\bullet \geq 30 \% \text { relative reduction } \\
\text { in hepatic fat on MRI- } \\
\text { PDFF } \\
- \text { MRE } \\
\text { ELF, } \\
\text { Fibrosure/Fibrotest, } \\
\text { cytokeratin, acylcarnitine }\end{array}$ & Decrease & $N A$ & $\begin{array}{c}\text { No effect on } \\
\text { liver } \\
\text { stiffness }\end{array}$ & $\begin{array}{l}\text { - Increased } \\
\text { triglycerides } \\
\text { - No changes in } \\
\text { glucose / insulin / } \\
\text { HbA1c }\end{array}$ & $\begin{array}{l}\text { No SAEs } \\
\text { reported } \\
\text { attributable to } \\
\text { drug } \\
\text { - Most common } \\
\text { SEs were } \\
\text { gastrointestinal } \\
\text { and headache }\end{array}$ \\
\hline Elafibranor & $\begin{array}{l}\text { PPAR- } \alpha /-\delta \\
\text { agonist }\end{array}$ & II & $\begin{array}{l}\text { - Reversal of NASH } \\
\text { without worsening of } \\
\text { fibrosis } \\
\text { - Change in NAS; change } \\
\text { in steatosis, ballooning, } \\
\text { inflammation, fibrosis; } \\
\text { liver enzymes; non- } \\
\text { invasive serum markers; } \\
\text { metabolic profile. }\end{array}$ & No effect & Decrease & $\begin{array}{c}\text { Small } \\
\text { decrease or } \\
\text { no effect }\end{array}$ & $\begin{array}{l}\text { Decreased LDL-C } \\
\text { - Decreased } \\
\text { triglycerides } \\
\text { - Decreased HbA1c }\end{array}$ & $\begin{array}{l}\text { Mild reversible } \\
\text { increase in serum } \\
\text { creatinine }\end{array}$ \\
\hline Cenicriviroc & $\begin{array}{l}\text { CCR2/CCR5 } \\
\text { antagonist }\end{array}$ & $\mathrm{IIb}$ & $\begin{array}{l}\text { - Improvement of NASH } \\
\text { without worsening of } \\
\text { fibrosis } \\
\text { - Resolution of NASH } \\
\text { without worsening of } \\
\text { fibrosis; improvement in } \\
\text { fibrosis of } \geq 1 \text { stage } \\
\text { without worsening in } \\
\text { NASH. }\end{array}$ & No effect & $\begin{array}{c}\text { Small } \\
\text { decrease or } \\
\text { no effect }\end{array}$ & $\begin{array}{c}\text { Modest } \\
\text { decrease }\end{array}$ & $\begin{array}{l}\text { No change in weight } \\
\text {-No change in } \\
\text { metabolic profile }\end{array}$ & $\begin{array}{l}\text { Serum rise in } \\
\text { amylase without } \\
\text { pancreatitis }\end{array}$ \\
\hline Selonsertib & ASK-1 inhibitor & II & $\begin{array}{l}\text { - Improvement in } \\
\text { histology } \\
\text { - Reduction in hepatic fat } \\
\text { on MRI-PDFF } \\
\text { - ELF } \\
\text { - FibroSure/FibroTest }\end{array}$ & No effect & No effect & Decrease & $\begin{array}{l}\text { No change in LDL- } \\
\text { C / trigylcerides / } \\
\text { HbA1c }\end{array}$ & $\begin{array}{l}\text { - Most common } \\
\text { SEs were } \\
\text { headache, } \\
\text { nausea and } \\
\text { sinusitis }\end{array}$ \\
\hline
\end{tabular}




\begin{tabular}{|c|c|c|c|c|c|c|}
\hline Emricasan & $\begin{array}{l}\text { Caspase } \\
\text { inhibitor }\end{array}$ & I & $\begin{array}{l}\text { Reduction in ALT } \\
\text { Change in AST, } \\
\text { caspase } 3 / 7, \text { cCK18, } \\
\text { flCK18 }\end{array}$ & $\begin{array}{l}- \\
(\text { Achieved primary outcome of reduction in } \\
\text { ALT) }\end{array}$ & $\begin{array}{l}\text { No change in LDL-C } \\
\text { / trigylcerides / HbA1c }\end{array}$ & $\begin{array}{l}\text { - Most SEs were } \\
\text { mild. } \\
\text { - Single SAE in } \\
\text { intervention arm } \\
\text { was considered } \\
\text { unrelated. }\end{array}$ \\
\hline
\end{tabular}

Abbreviations: ACC, Acetyl-coenzyme A carboxylase; ASK-1, Apoptosis signal-regulating kinase 1; CCR2/CCR5, CC chemokine receptor types 2 and 5; CVD, cardiovascular disease ELF, Enhanced Liver Fibrosis score; FGF-19, Fibroblast growth factor 19; FXR, Farnesoid X receptor; LDL-C, low density lipoprotein cholesterol, MRE, magnetic resonance elastography; MRI-PDFF, MRI protein density fat fraction; NAS, NAFLD Activity Score; PPAR- $\alpha /-\delta$, Peroxisome proliferator-activated receptor- $\alpha$ and $-\delta$; SAE, serious adverse event; T2DM, type 2 diabetes mellitus; THR- $\beta$, Thyroid hormone receptor-beta; TLR, Toll-like receptor

*Presented in abstract. Await complete results.

\begin{tabular}{|c|c|c|c|c|c|c|c|c|c|}
\hline $\begin{array}{c}\text { TRIAL } \\
\text { IDENTIFIER }\end{array}$ & PHASE & TARGET & DRUG & $\begin{array}{l}\text { PATIENT } \\
\text { GROUP }\end{array}$ & $\begin{array}{l}\text { OUTCOME } \\
\text { MEASURES }\end{array}$ & STATUS & $n$ & $\begin{array}{l}\text { ESTIMATED } \\
\text { COMPLETION } \\
\text { DATE }\end{array}$ & $\begin{array}{c}\text { POTENTIAL } \\
\text { CHALLENGES / OTHER } \\
\text { BENEFITS }\end{array}$ \\
\hline NCT03646292 & IV & $\begin{array}{l}\cdot \text { •SGLT2i } \\
\text { •TZD }\end{array}$ & $\begin{array}{l}\text {-Epaglifozin } \\
\text {-Pioglitazone }\end{array}$ & $\begin{array}{l}\text { Patients with both } \\
\text { T2DM and } \\
\text { NAFLD }\end{array}$ & $\begin{array}{l}\text { - Liver fat change } \\
\text { measured by MRI- } \\
\text { PDFF }\end{array}$ & $\begin{array}{l}\text { Not yet } \\
\text { recruiting }\end{array}$ & 60 & Feb 2021 & $\begin{array}{l}\text { Potential of risk fractures, } \\
\text { weight gain and urinary } \\
\text { tract infections, improved }\end{array}$ \\
\hline
\end{tabular}




\begin{tabular}{|c|c|c|c|c|c|c|c|c|c|}
\hline & & & & & $\begin{array}{l}\text {-MRE, lipids, LFTs, } \\
\text { HbA1c, insulin, CRP }\end{array}$ & & & & $\begin{array}{l}\text { glucose tolerance, } \\
\text { decreased CVD risk }\end{array}$ \\
\hline NCT03434613 & IV & $\begin{array}{l}\text {-HMG-CoA } \\
\text { reductase } \\
\text { inhibitor } \\
\text {-NPC1L1i }\end{array}$ & •Ezetimibe & $\begin{array}{l}\text { Patient with both } \\
\text { hyperlipidaemia } \\
\text { and NAFLD }\end{array}$ & $\begin{array}{l}\text { - Liver fat change } \\
\text { measured by MRI- } \\
\text { PDFF } \\
\text { •MRE }\end{array}$ & Recruiting & 70 & Jan 2020 & $\begin{array}{c}\text { Muscle aches and } \\
\text { previously no mortality } \\
\text { benefit in NAFLD treated } \\
\text { with lipid lowering drugs }\end{array}$ \\
\hline NCT03776175 & Illa & $\begin{array}{l}\cdot \text {-ACCi } \\
\cdot D G A T i\end{array}$ & $\begin{array}{l}\text { •PF05221304 } \\
\text { •PF06865571 }\end{array}$ & $\begin{array}{l}\text { Patients with } \\
\text { NAFLD }\end{array}$ & $\begin{array}{l}\text { - Liver fat change } \\
\text { measured by MRI- } \\
\text { PDFF }\end{array}$ & Recruiting & 98 & Oct 2019 & $\begin{array}{c}\text { Increase plasma ketone } \\
\text { bodies, increase hepatic } \\
\text { inflammation, improved } \\
\text { glucose tolerance }\end{array}$ \\
\hline NCT03517540 & II & $\begin{array}{l}\text {-CCR2/CCR5a } \\
\text {-FXRa }\end{array}$ & $\begin{array}{l}\text {-Cencriviroc } \\
\text {-Tropifexor }\end{array}$ & $\begin{array}{l}\text { NASH with F2/F3 } \\
\text { fibrosis on biopsy }\end{array}$ & -Adverse events & Recruiting & 200 & Sep 2020 & $\begin{array}{l}\text { Increased LDL-C, pruritus, } \\
\text { increase serum amylase }\end{array}$ \\
\hline NCT03449446 & II & $\begin{array}{l}\text {-ASK-1i } \\
\text {-ACCi } \\
\text {-FXRa }\end{array}$ & $\begin{array}{l}\text {-Selonsertib } \\
\text { •GS-0976 } \\
\text { •GS-9674 }\end{array}$ & $\begin{array}{l}\text { NASH with F3/F4 } \\
\text { fibrosis on biopsy }\end{array}$ & $\begin{array}{l}\text {-Adverse events, } \\
\text { laboratory } \\
\text { abnormalities, } \geq 1 \text { - } \\
\text { Stage Improvement } \\
\text { in fibrosis without } \\
\text { worsening of NASH }\end{array}$ & $\begin{array}{l}\text { Active, } \\
\text { not } \\
\text { recruiting }\end{array}$ & 395 & Oct 2019 & $\begin{array}{l}\text { Increase plasma ketone } \\
\text { bodies, potential treatment } \\
\text { of hypertriglyceridaemia, } \\
\text { improved glucose tolerance }\end{array}$ \\
\hline NCT03987074 & II & $\begin{array}{l}\text {-GLP-1a } \\
\text {-ACCi } \\
\text {-FXRa }\end{array}$ & $\begin{array}{l}\text {-Semaglutide } \\
\text {-GS-0976 } \\
\text {-GS-9674 }\end{array}$ & $\begin{array}{l}\text { NASH with F2/F3 } \\
\text { fibrosis: } \\
\text { 1) on biopsy, or } \\
\text { 2) MRI-PDFF / } \\
\text { Fibroscan }\end{array}$ & $\begin{array}{l}\text { Treatment } \\
\text { emergent adverse } \\
\text { events }\end{array}$ & $\begin{array}{l}\text { Not yet } \\
\text { recruiting }\end{array}$ & 100 & July 2020 & $\begin{array}{c}\text { Nausea, increase plasma } \\
\text { ketone bodies, potential } \\
\text { treatment of } \\
\text { hypertriglyceridaemia, } \\
\text { increase LDL-C, pruritus }\end{array}$ \\
\hline
\end{tabular}


1. Ludwig J, Viggiano TR, McGill DB, et al. Nonalcoholic steatohepatitis: Mayo Clinic experiences with a hitherto unnamed disease. Mayo Clin. Proc. 55, 434-8 (1980).

2. Vernon G, Baranova A \& Younossi ZM. Systematic review: The epidemiology and natural history of non-alcoholic fatty liver disease and non-alcoholic steatohepatitis in adults.

Aliment. Pharmacol. Ther. 34, 274-285 (2011).

3. Byrne CD \& Targher G. NAFLD: A multisystem disease. Journal of Hepatology 62, S47-S64 (2015).

4. Younossi Z, Anstee QM, Marietti M, et al. Global burden of NAFLD and NASH: Trends, predictions, risk factors and prevention. Nat. Rev. Gastroenterol. Hepatol. 15, 11-20 (2018).

5. Shingina A, Dewitt PE, Dodge JL, et al. Future Trends in Demand for Liver Transplant: Birth Cohort Effects among Patients with NASH and HCC. Transplantation 103, 140-148 (2019).

6. DeFronzo RA, Inzucchi S, Abdul-Ghani M, et al. Pioglitazone: The forgotten, cost-effective cardioprotective drug for type 2 diabetes. Diabetes Vasc. Dis. Res. 16, 133-143 (2019).

7. Abdul-Ghani M, DeFronzo RA, Del Prato S, et al. Cardiovascular disease and type 2 diabetes: Has the dawn of a new era arrived? Diabetes Care 40, 813-820 (2017).

8. Harrison SA, Rossi SJ, Paredes AH, et al. NGM282 Improves Liver Fibrosis and Histology in 12 Weeks in Patients With Nonalcoholic Steatohepatitis. Hepatology hep.30590 (2019). doi:10.1002/hep.30590*

9. Kir S, Kliewer SA \& Mangelsdorf DJ. Roles of FGF19 in liver metabolism. Cold Spring Harb. Symp. Quant. Biol. 76, 139-144 (2011).

10. Liu W-Y, Xie D-M, Zhu G-Q, et al. Targeting fibroblast growth factor 19 in liver disease: a potential biomarker and therapeutic target. Expert Opin. Ther. Targets 19, 675-685 (2015).

11. Rinella ME, Trotter JF, Abdelmalek MF, et al. Rosuvastatin improves the FGF19 analogue NGM282-associated lipid changes in patients with non-alcoholic steatohepatitis. J. Hepatol. 70, 735-744 (2019).

12. Sanyal A, Charles ED, Neuschwander-Tetri BA, et al. Pegbelfermin (BMS-986036), a PEGylated fibroblast growth factor 21 analogue, in patients with non-alcoholic steatohepatitis: a randomised, double-blind, placebo-controlled, phase 2 a trial. Lancet 392 , 2705-2717 (2018).

13. Gaich G, Chien JY, Fu H, et al. The effects of LY2405319, an FGF21 Analog, in obese human subjects with type 2 diabetes. Cell Metab. 18, 333-340 (2013).

14. Loomba R, Neutel J, Mohseni R, et al. LBP-20-VK2809, a Novel Liver-Directed Thyroid Receptor Beta Agonist, Significantly Reduces Liver Fat with Both Low and High Doses in Patients with Non-Alcoholic Fatty Liver Disease: A Phase 2 Randomized, PlaceboControlled Trial. J. Hepatol. 70, e150-e151 (2019).

15. Harrison S, Moussa S, Bashir M, et al. MGL-3196, a selective thyroid hormone receptorbeta agonist significantly decreases hepatic fat in NASH patients at 12 weeks, the primary endpoint in a 36 week serial liver biopsy study. J. Hepatol. 68, S38 (2018).

16. Vatner DF, Weismann D, Beddow SA, et al. Thyroid hormone receptor- $\beta$ agonists prevent hepatic steatosis in fat-fed rats but impair insulin sensitivity via discrete pathways. Am. J. Physiol. Metab. 305, E89-E100 (2013).

17. Donnelly KL, Smith CI, Schwarzenberg SJ, et al. Sources of fatty acids stored in liver and secreted via lipoproteins in patients with nonalcoholic fatty liver disease. J. Clin. Invest. 115, 1343-1351 (2005).

18. Loomba R, Kayali Z, Noureddin M, et al. GS-0976 Reduces Hepatic Steatosis and Fibrosis Markers in Patients With Nonalcoholic Fatty Liver Disease. Gastroenterology 155, 14631473.e6 (2018).*

19. Ratziu V, Harrison SA, Francque S, et al. Elafibranor, an Agonist of the Peroxisome Proliferator-Activated Receptor- $\alpha$ and $-\delta$, Induces Resolution of Nonalcoholic Steatohepatitis Without Fibrosis Worsening. Gastroenterology 150, 1147-1159.e5 (2016).

20. Friedman SL, Ratziu V, Harrison SA, et al. A randomized, placebo-controlled trial of cenicriviroc for treatment of nonalcoholic steatohepatitis with fibrosis. Hepatology 67, 17541767 (2018). 
21. Loomba R, Lawitz E, Mantry PS, et al. The ASK1 inhibitor selonsertib in patients with nonalcoholic steatohepatitis: A randomized, phase 2 trial. Hepatology 67, 549-559 (2018).

22. Shiffman M, Freilich $B$, Vuppalanchi $R$, et al. Randomised clinical trial: emricasan versus placebo significantly decreases ALT and caspase 3/7 activation in subjects with nonalcoholic fatty liver disease. Aliment. Pharmacol. Ther. 49, 64-73 (2019).

23. Conatus Announces Top-line Results from ENCORE-NF Phase $2 \mathrm{~b}$ Clinical Trial in NASH Fibrosis | Conatus Pharmaceuticals. Available at: https://ir.conatuspharma.com/newsreleases/news-release-details/conatus-announces-top-line-results-encore-nf-phase-2bclinical. (Accessed: 24th June 2019)

24. Younossi Z, Ratziu V, Loomba R, et al. GS-06-Positive Results from REGENERATE: A Phase 3 International, Randomized, Placebo-Controlled Study Evaluating Obeticholic Acid Treatment for NASH. J. Hepatol. 70, e5 (2019). **

25. Neuschwander-Tetri BA, Loomba R, Sanyal AJ, et al. Farnesoid X nuclear receptor ligand obeticholic acid for non-cirrhotic, non-alcoholic steatohepatitis (FLINT): A multicentre, randomised, placebo-controlled trial. Lancet 385, (2015). ${ }^{* *}$

26. Glen J, Floros L, Day C, et al. Non-alcoholic fatty liver disease (NAFLD): Summary of NICE guidance. BMJ (Online) 354, (2016).

27. EASL, EASD \& EASO. European Association For The Study Of The Liver (EASL) European Association For The Study Of Diabetes (EASD) - European Association For The Study Of Obesity (EASO): Clinical Practice Guidelines for the management of non-alcoholic fatty liver disease. Diabetologia 59, 1121-1140 (2016).

28. Naga C, Zobair Y, E. LJ, et al. The diagnosis and management of non-alcoholic fatty liver disease: Practice Guideline by the American Association for the Study of Liver Diseases, American College of Gastroenterology, and the American Gastroenterological Association. Hepatology 55, 2005-2023 (2012).

29. Cusi K, Orsak B, Bril F, et al. Long-term pioglitazone treatment for patients with nonalcoholic steatohepatitis and prediabetes or type 2 diabetes mellitus a randomized trial. Ann. Intern. Med. 165, 305-315 (2016).

30. Sanyal AJ, Chalasani N, Kowdley K V., et al. Pioglitazone, vitamin E, or placebo for nonalcoholic steatohepatitis. N. Engl. J. Med. 362, 1675-1685 (2010).

31. Belfort R, Harrison SA, Brown K, et al. A placebo-controlled trial of pioglitazone in subjects with nonalcoholic steatohepatitis. N. Engl. J. Med. 355, 2297-2307 (2006).

32. Musso G, Cassader M, Paschetta E, et al. Thiazolidinediones and advanced liver fibrosis in nonalcoholic steatohepatitis: A meta-analysis. JAMA Intern. Med. 177, 633-640 (2017).**

33. DeFronzo RA, Inzucchi S, Abdul-Ghani M, et al. Pioglitazone: The forgotten, cost-effective cardioprotective drug for type 2 diabetes. Diabetes Vasc. Dis. Res. 16, 133-143 (2019).

34. Mahady SE, Webster AC, Walker S, et al. The role of thiazolidinediones in non-alcoholic steatohepatitis - A systematic review and meta analysis. J. Hepatol. 55, 1383-1390 (2011).

35. Young LH, Viscoli CM, Schwartz GG, et al. Heart failure after ischemic stroke or transient ischemic attack in insulin-resistant patients without diabetes mellitus treated with pioglitazone. Circulation 138, 1210-1220 (2018).

36. Armstrong MJ, Gaunt P, Aithal GP, et al. Liraglutide safety and efficacy in patients with nonalcoholic steatohepatitis (LEAN): A multicentre, double-blind, randomised, placebocontrolled phase 2 study. Lancet 387, 679-690 (2016).

\section{REFERENCE ANNOTATIONS $\left({ }^{*}=\right.$ of importance, ${ }^{* *}=$ of considerable importance)}

${ }^{* *}$ Musso G, Cassader M, Paschetta E, et al. Thiazolidinediones and advanced liver fibrosis in nonalcoholic steatohepatitis: A meta-analysis. JAMA Intern. Med. 177, 633-640 (2017). 
The PIVENS trial ${ }^{30}$ demonstrated an improvement in steatosis and steatohepatitis in patients with NASH treated with pioglitazone. However, the PIVENS tria/ ${ }^{30}$ was unable to demonstrate a significant improvement in fibrosis stage in patients with NASH treated with pioglitazone. This metaanalysis by Musso et al demonstrates that thiazolidinediones also improve advanced fibrosis in patients with $\mathrm{NASH}$.

${ }^{* *}$ Neuschwander-Tetri BA, Loomba R, Sanyal AJ, et al. Farnesoid X nuclear receptor ligand obeticholic acid for non-cirrhotic, non-alcoholic steatohepatitis (FLINT): A multicentre, randomised, placebo-controlled trial. Lancet 385, (2015)

The FLINT trial is of considerable importance because it demonstrated OCA improved NAS in participants without worsening of fibrosis. It also highlighted two of the foremost challenges with OCA, namely pruritus and deterioration in lipid profile.

**Younossi Z, Ratziu V, Loomba R, et al. GS-06-Positive Results from REGENERATE: A Phase 3 International, Randomized, Placebo-Controlled Study Evaluating Obeticholic Acid Treatment for NASH. J. Hepatol. 70, e5 (2019)

REGENERATE is of considerable importance because interim analysis suggest OCA may be the first drug eligible to apply for accelerate approval. However, interim analysis did not demonstrate an improvement in NAS in participants treated with OCA. We await future complete peer reviewed reporting.

*Loomba R, Kayali Z, Noureddin M, et al. GS-0976 Reduces Hepatic Steatosis and Fibrosis Markers in Patients With Nonalcoholic Fatty Liver Disease. Gastroenterology 155, 1463-1473.e6 (2018) GS-9674 is of importance because it caused a significant improvement in hepatic steatosis in patients with NASH. There are two planned trials of combination therapy in which GS-9674 will be one of the combination drugs.

*Harrison SA, Rossi SJ, Paredes AH, et al. NGM282 Improves Liver Fibrosis and Histology in 12 Weeks in Patients With Nonalcoholic Steatohepatitis. Hepatology hep.30590 (2019).

doi:10.1002/hep.30590

This study is of importance because it demonstrates a significant improvement in both steatosis and fibrosis. However, the most common side-effect was diarrhoea, and weight loss was not measured. Therefore, it will be important to assess change in weight in patients in future studies of NGM282, in order to ascertain whether diarrhoea-mediated weight loss is contributing to improvements in liver histology. 